\title{
BMJ Open Phenylketonuria incidence in China between 2013 and 2017 based on data from the Chinese newborn screening information system: a descriptive study
}

\author{
Liangcheng Xiang, ${ }^{1}$ Jing Tao, ${ }^{1}$ Kui Deng, ${ }^{1}$ Xiaohong Li, ${ }^{1} \mathrm{Qi} \mathrm{Li},{ }^{1}$ Xuelian Yuan, ${ }^{1}$ \\ Juan Liang, ${ }^{1}$ Erling Yu, ${ }^{1}$ Meixian Wang, ${ }^{1}$ Huiqing Wang, ${ }^{2}$ Hanmin Liu, ${ }^{2,3}$ Jun $Z \mathrm{hu}^{1,3}$
}

To cite: Xiang L, Tao J, Deng K, et al. Phenylketonuria incidence in China between 2013 and 2017 based on data from the Chinese newborn screening information system: a descriptive study. BMJ Open 2019;9:e031474. doi:10.1136/ bmjopen-2019-031474

- Prepublication history for this paper is available online. To view these files, please visit the journal online (http://dx.doi. org/10.1136/bmjopen-2017031474).

Received 08 May 2019 Revised 02 July 2019 Accepted 17 July 2019

Check for updates

(C) Author(s) (or their employer(s)) 2019. Re-use permitted under CC BY-NC. No commercial re-use. See rights and permissions. Published by BMJ.

${ }^{1}$ National Office for Maternal and Child Health Surveillance of China, Sichuan University West China Second University Hospital, Chengdu, China ${ }^{2}$ Department of Pediatrics, Sichuan University West China Second University Hospital, Chengdu, China

${ }^{3}$ Key Laboratory of Birth Defects and Related Diseases of Women and Children (Sichuan University), Ministry of Education, Sichuan University West China Second University Hospital, Chengdu, China

Correspondence to Jun Zhu; zhujun028@163.com

\section{ABSTRACT}

Objective This study examines the incidence and spatial clustering of phenylketonuria (PKU) in China between 2013 and 2017.

Methods Data from the Chinese Newborn Screening Information System were analysed to assess PKU incidence with $95 \%$ Cls by province, region and disease severity. Spatial clustering of PKU cases was analysed using global and local spatial autocorrelation analysis in the geographic information system.

Results The database contained 4925 neonates with confirmed PKU during the study period, corresponding to an incidence of 6.28 (95\% Cl: 6.11 to 6.46) per 100000 neonates screened. Incidence was highest in the provinces of Gansu, Ningxia and Qinghai, where it ranged from 19.00 to 28.63 per 100000 neonates screened. Overall incidence was higher in the northern part of the country, where classical disease predominated, than in the southern part, where mild disease predominated. PKU cases clustered spatially (global Moran's $1=0.3603, Z=5.3097, p<0.001$ ), and local spatial autocorrelation identified four northern provinces as high-high clusters (Gansu, Qinghai, Ningxia and Shanxi).

Conclusions China shows an intermediate PKU incidence among countries, and incidence differs substantially among Chinese provinces and between northern and southern regions. Our results suggest the need to focus efforts on screening, diagnosing and treating PKU in highincidence provinces.

\section{INTRODUCTION}

Phenylketonuria (PKU; OMIM 261600), an autosomal recessive disease, results mainly from mutations in, or deletion of, the gene encoding phenylalanine hydroxylase (PAH). ${ }^{1}$ If left untreated, PKU can irreversibly damage the central nervous system to varying degrees and lead to intellectual disability, mental disorders, behavioural problems and seizures, ${ }^{2}$ which not only reduce quality of neonatal life but also place a severe financial burden on the families. ${ }^{3}$

Early dietary therapy can effectively reduce damage to the nervous system and

\section{Strengths and limitations of this study}

- The study covers the largest, most geographically extensive newborn population in mainland China because it draws on the Chinese Newborn Screening Information System.

- The study provides the most comprehensive view of phenylketonuria (PKU) incidence by province, region and disease severity between 2013 and 2017 across China.

- The study explored spatial clustering of PKU cases using global and local spatial autocorrelation analysis.

- The north-south differences in PKU incidence may be confounded in this study by lower screening rates in some areas than in some provinces showing high incidence.

improve prognosis,${ }^{45}$ highlighting the need for early PKU screening and diagnosis. ${ }^{6}$ Newborn screening programme has been in place in western Europe and North America for decades, ${ }^{78}$ but they did not start in China until 1981 and in the ensuing two decades, they expanded to all 31 provinces. ${ }^{9}$ Screening coverage across the country has increased from less than $10 \%$ before 2001 to $36.96 \%$ by 2007 and to $96.1 \%$ in $2016 .^{10-12}$ However, there remain strong regional inequities in healthcare infrastructure and access, so screening rates can be lower in some areas, especially in remote western parts. ${ }^{12}$

Despite these advances in screening, recent nation-wide data on PKU incidence are lacking. Data collected by the National Centre for Clinical Laboratories from particular regions indicated an incidence of 8.64 per 100000 neonates screened for the period 1985-2007,,$^{13}$ compared with 8.50 per 100000 for the period 2000-2007. ${ }^{14}$ Data from 193 Chinese neonatal screening laboratories 
indicated an incidence of 8.2 per 100000 neonates in 2013, when the screening coverage was approximately $86 \%-88 \%{ }^{15}$ More recent nation-wide data are needed to gain an accurate picture of PKU in China. At the same time, the geographical distribution of the disease needs to be much better understood because China shows substantial inequalities in healthcare resources and disease epidemiology between urban and rural areas, and between north and south. Such knowledge may help guide rational allocation of resources and efforts aimed at PKU screening and early diagnosis.

To begin to address these gaps, the aim of this present study is to investigate the incidence of PKU in China for the period 2013-2017 using data from the National Newborn Screening Programme, and to analyse the global and local spatial distribution of the disease.

\section{METHODS}

\section{Data collection}

The data in this study were extracted from the Chinese Newborn Screening Information System (CNBSIS), based at the National Office of Maternal and Child Health Surveillance. The CNBSIS covers $>95 \%$ of districts/ counties in 30 provinces and includes 230 newborn screening centres covering $>90 \%$ of the newborn population in mainland China. ${ }^{16}$ The exception is Tibet, where screening centres did not open until 2015 and are still too sparse to provide accurate data on PKU incidence. Data from blood sampling cards, laboratory test reports and medical records were entered in the CNBSIS by trained staff at local newborn screening centres in each province. The quality and accuracy of data entry were checked at the provincial level by experienced doctors at provincial newborn screening centres. More details about data collection and quality control have been described elsewhere. ${ }^{16}$

\section{PKU diagnosis}

PKU was diagnosed based on the criteria in the 2010 edition of the "National Newborn Screening Guidelines,"17 from the Chinese Ministry of Health. Neonates were diagnosed with this disease if phenylalanine concentration in blood exceeded $360 \mu \mathrm{mol} / \mathrm{L}$ and tetrahydrobiopterin-deficient hyperphenylalaninaemia was excluded. In some analyses, PKU cases were stratified based on pretreatment plasma phenylalanine concentration into mild disease $(360-1200 \mu \mathrm{mol} / \mathrm{L})$ or classical disease $(>1200$ $\mathrm{\mu mol} / \mathrm{L}){ }^{1819}$

\section{Statistical analysis}

Statistical analyses were performed using SAS V.9.4 (SAS Institute, Cary, NC, USA). Incidence of PKU was reported as the number of PKU cases diagnosed (c), divided by the number of newborns screened (b). The corresponding $95 \%$ CIs were calculated as follows ${ }^{20}$ :

$$
\text { lower limit }=\mathrm{c} \times\left(1-\frac{1}{\mathrm{ac}}-\frac{1.96}{3} \sqrt{\frac{1}{\mathrm{c}}}\right)^{3} / \mathrm{b} \times 100000
$$

and

upper limit $=(\mathrm{c}+1) \times\left(1-\frac{1}{\mathrm{a}(\mathrm{c}+1)}+\frac{1.96}{3} \sqrt{\frac{1}{\mathrm{c}+1}}\right)^{3} / \mathrm{b} \times 100000$

For analyses of the spatial distribution of PKU cases, provinces in mainland China were divided $^{21}$ into a southern region (Jiangsu, Anhui, Hubei, Chongqing, Sichuan, Tibet, Yunnan, Guizhou, Hunan, Jiangxi, Guangxi, Guangdong, Fujian, Zhejiang, Shanghai and Hainan) or northern region (Shandong, Henan, Shanxi, Shaanxi, Gansu, Qinghai, Xinjiang, Hebei, Tianjin, Beijing, Inner Mongolia, Liaoning, Jilin, Heilongjiang and Ningxia). Global and local spatial autocorrelation of PKU incidence for the study period was assessed based on global and local Moran's I values ${ }^{22}$ as calculated in ArcGIS V.10.2 (ESRI, Redlands, CA, USA). Geographical data to generate maps were taken from the National Geomatics Centre of China (http://ngcc.sbsm.gov.cn).

\section{Patient and public involvement}

Patients and members of the public were not involved in the design of this study.

\section{RESULTS}

\section{PKU incidence in China from 2013 to 2017}

During 2013-2017, approximately 83.8 million babies were born in China, of which 78.4 million (93.55\%) were screened and registered in the CNBSIS. Over the entire country, PKU incidence was 6.28 (95\% CI: 6.11 to 6.46) per 100000 neonates screened (table 1). Among 30 provinces and municipalities, incidence was highest in Gansu (28.63, 95\% CI: 25.98 to 31.48), followed by Ningxia (19.00, 95\% CI: 15.34 to 23.28 ) and Qinghai (17.37, 95\% CI: 12.81 to 23.03). Incidence was lowest in Guangdong and Guangxi (<1 per 100000 neonates screened). The proportion of PKU cases that were classical exceeded $50 \%$ in 17 of 30 provinces and municipalities.

To gain insights into larger-scale trends in PKU incidence in China, we collapsed the provinces and municipalities into northern and southern blocs (table 2). The north showed significantly higher incidence of mild and classical PKU than the south. Within the north, classical disease was present at significantly higher incidence than mild disease while the converse was observed in the south.

\section{Spatial clustering of PKU in China from 2013 to 2017}

Across the entire country during the study period, moderately positive global spatial autocorrelation was observed, based on global Moran's I (0.3603, Z=5.3097, $\mathrm{p}<0.001$; figure 1). Analysis of local Moran's I on univariate local indicator of spatial association maps identified high-high $(\mathrm{HH})$ and low-low (LL) cluster areas (figure 2). $\mathrm{HH}$ clusters encompassed four northern provinces (Gansu, Qinghai, Ningxia and Shanxi), whereas LL clusters included seven southern provinces 
Table 1 Incidence of PKU in China by province and severity, 2013-2017

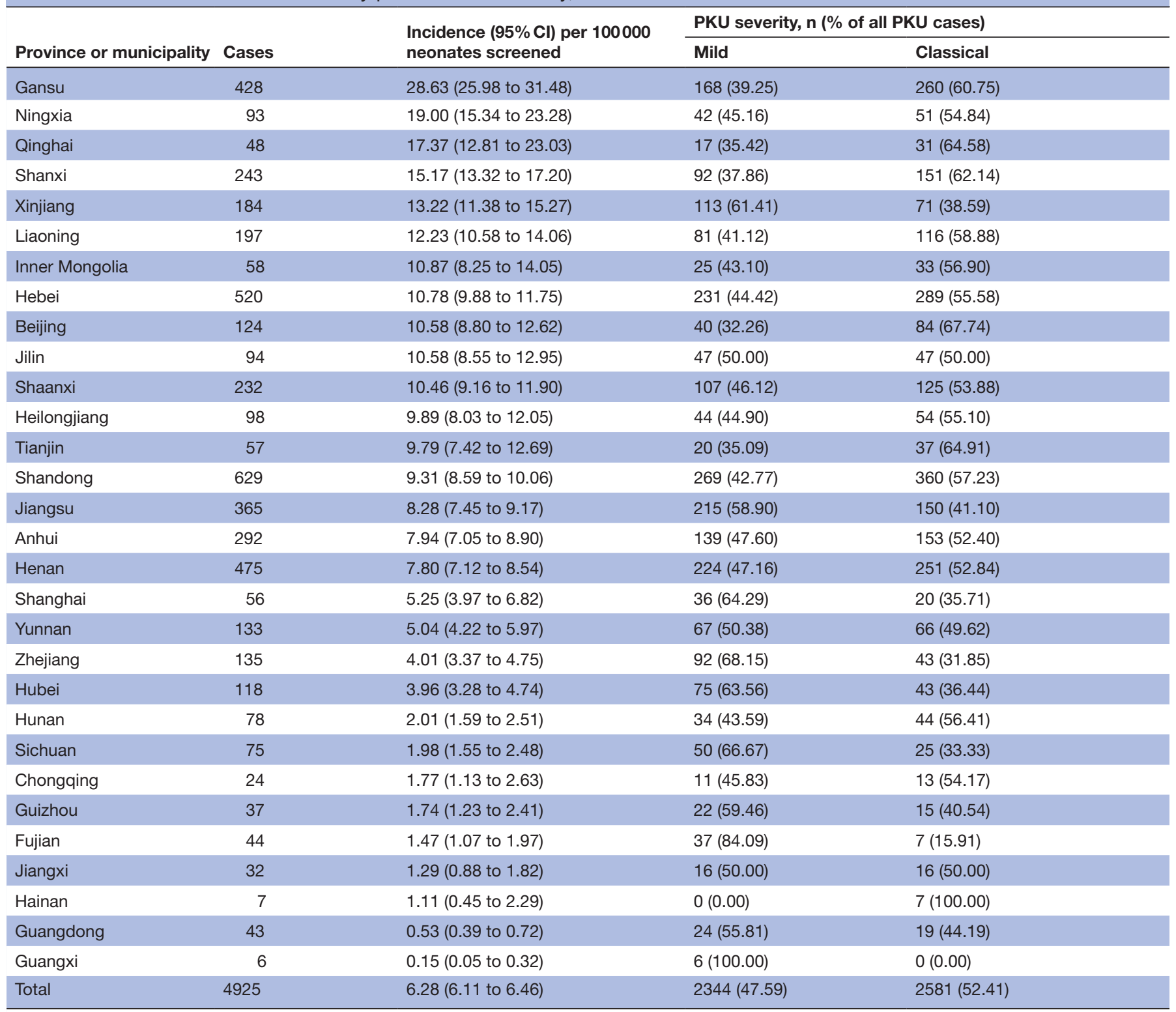

$\mathrm{Cl}$, Confidence Interval; PKU, phenylketonuria.

(Guizhou, Hunan, Jiangxi, Guangxi, Guangdong,

Fujian and Hainan).

\section{DISCUSSION}

Our comprehensive analysis of CNBSIS data for 20132017 suggests a nation-wide PKU incidence of 6.28 per
100000 neonates screened in China. Incidence differed significantly between the north and south of the country, with high-incidence provinces being Gansu, Ningxia, and Qinghai, and low-incidence provinces being Guangdong and Guangxi. The provinces of Gansu, Ningxia, Qinghai and Shanxi appear to be HH cluster type. These

Table 2 Incidence of PKU in China by north/south region and severity, 2013-2017

\begin{tabular}{|c|c|c|c|c|}
\hline \multirow[b]{2}{*}{ Region } & \multicolumn{2}{|l|}{ Mild PKU } & \multicolumn{2}{|l|}{ Classical PKU } \\
\hline & Cases, n (95\% Cl) & $\begin{array}{l}\text { Incidence }(95 \% \mathrm{Cl}) \text { per } 100000 \\
\text { neonates screened }\end{array}$ & Cases, n $(95 \% \mathrm{Cl})$ & $\begin{array}{l}\text { Incidence }(95 \% \mathrm{Cl}) \text { per } 100000 \\
\text { neonates screened }\end{array}$ \\
\hline North & 1520 (1444 to 1596$)$ & $4.92(4.67$ to 5.17$)$ & 1960 (1873 to 2047$)$ & 6.34 (6.06 to 6.63$)$ \\
\hline Total & 2344 (2249 to 2439 ) & 2.99 (2.87 to 3.11$)$ & 2581 (2481 to 2681 ) & 3.29 (3.16 to 3.42$)$ \\
\hline
\end{tabular}

$\mathrm{Cl}$, Confidence Interval; PKU, phenylketonuria. 


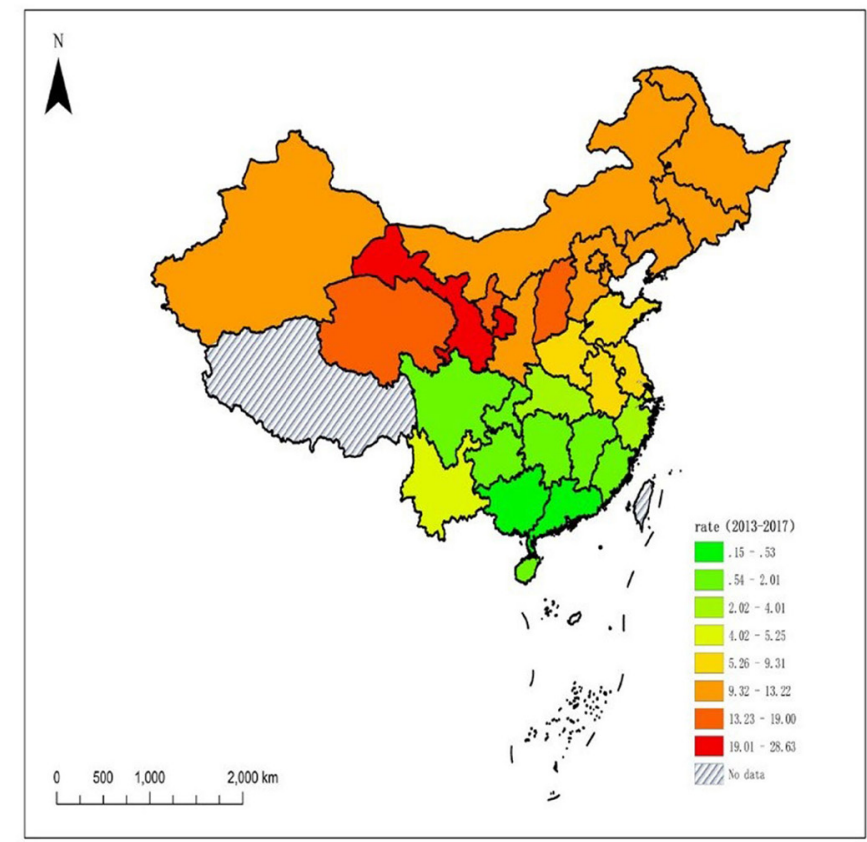

Figure 1 Spatial distribution of phenylketonuria incidence in China, 2013-2017.

results place China near the middle of countries and populations for which PKU incidence has been reported (figure 3). ${ }^{22-25}$ The large variation in incidence around the world may reflect ethnic and geographical differences in polymorphisms of the PAH gene. ${ }^{26-28}$ For example, incidence is higher among Caucasians than other populations. ${ }^{29}{ }^{30}$ Studies to identify genetic risk factors for PKU, and particularly the more severe classical disease,

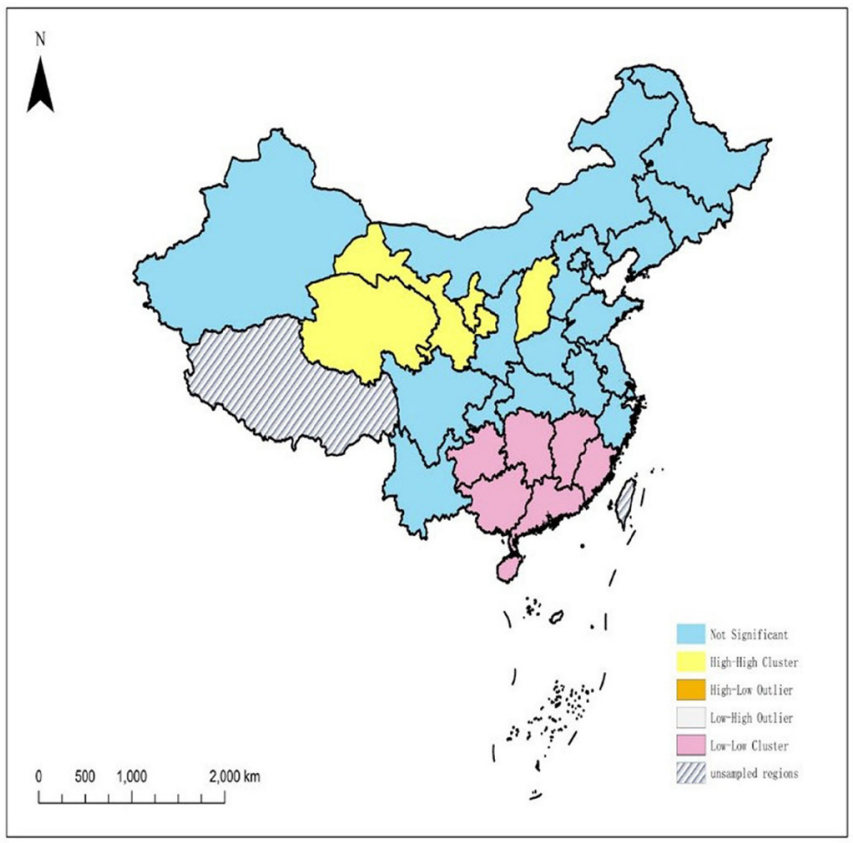

Figure 2 Univariate local indicator of spatial association cluster map of phenylketonuria incidence in China, 20132017.

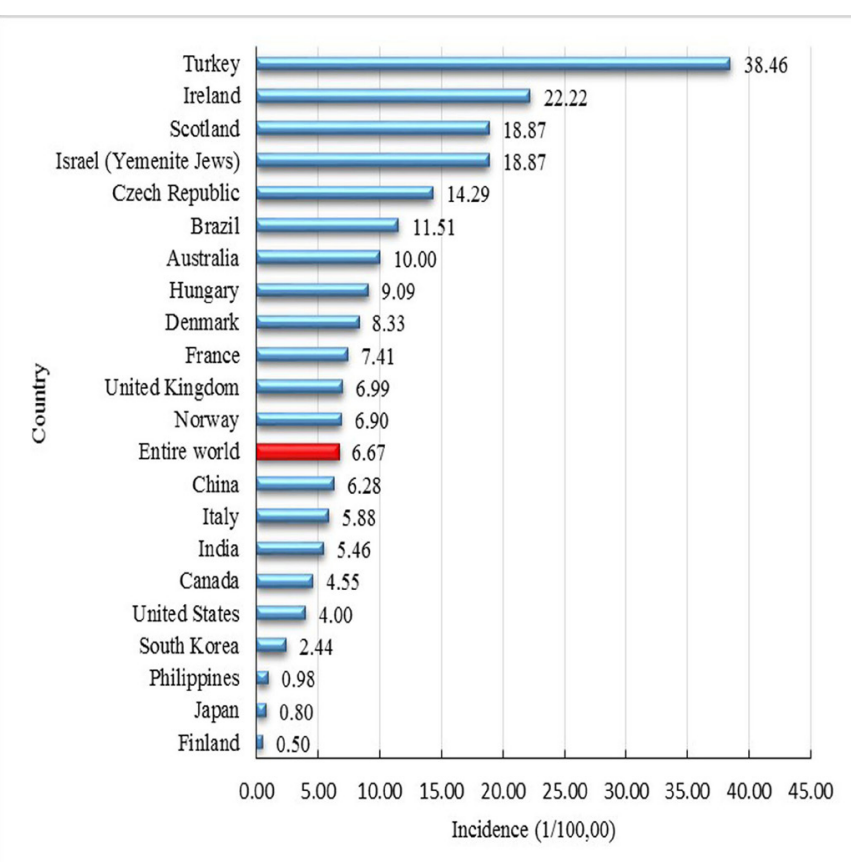

Figure 3 Phenylketonuria incidence by country.

are urgently needed. They may lead to reliable genetic screening of newborns.

We measured slightly lower nation-wide PKU incidence than previous studies in China. ${ }^{13-15}$ Our results are likely to be more reliable because we included only neonates diagnosed with PKU, not those diagnosed with tetrahydrobiopterin deficiency, in contrast to two of those studies. ${ }^{14}{ }^{15}$ In addition, neonatal screening coverage was higher during our study period of 2007-2013 than during the earlier periods in two of those studies. ${ }^{13} 14$

The five high-incidence provinces in our study (Gansu, Ningxia, Qinghai, Shanxi and Xinjiang) have incidences similar to those of several high-incidence areas such as Ireland, Scotland, Israel (Yemenite Jews) and Czech Republic. The high proportion of Hui, Uyghur and other minority populations in these five Chinese provinces may help explain the higher PKU incidence. For example, in Ningxia, incidence is much higher among Hui than among the Han majority, ${ }^{31}$ and Uyghurs share consanguity with Caucasians, ${ }^{32}$ suggesting that they may also show higher incidence than other populations. Future studies should examine these possibilities in greater detail. Our observation that all five high-incidence provinces lie in northern China is likely no coincidence, consistent with a previous study. ${ }^{9}$ The northern region is generally less developed than the southern, with lower per-capita income (with the notable exception of Beijing and Shanghai) and less access to medical facilities and public health infrastructure such as screening. In addition, neonatal screening coverage is substantially lower in inland areas than in coastal areas. ${ }^{12}$ Our data suggest that efforts at PKU screening and diagnosis need to be improved in the north, not only because overall PKU 
incidence is higher there but also because the incidence of classical disease exceeds that of mild disease.

Our analysis suggests that PKU cases in China show positive global spatial autocorrelation, which may reflect that the disease is an autosomal recessive, monogenic disorder, so its incidence is determined primarily by the presence of the disease allele in both parents rather than by environmental factors. The clustering revealed $\mathrm{HH}$ clusters in the northern provinces of Gansu, Ningxia, Qinghai and Shanxi, whereas LL clusters were identified in the south (Guizhou, Hunan, Jiangxi, Guangxi, Guangdong, Fujian and Hainan). These results further emphasise the need for greater screening and early diagnosis measures in the north, together with greater support interventions for families of affected children.

Although our analysis provides the most comprehensive insights so far into PKU incidence and severity across China, the data have some limitations. Differences in neonatal screening coverage may bias our findings and, because coverage correlates with access to healthcare resources, it may confound our analyses of north-south differences. Another potential confounder are differences in how often neonates were recalled for definitive diagnosis of PKU following a positive result on initial screening. Nevertheless, we consider such confounding to be minimal, given that the recall rate exceeded $85 \%$ in most provinces during the study period. Since CNBSIS does not record the nationality of each parent individually, we could not perform more detailed analyses of ethnicity on PKU incidence or severity.

\section{CONCLUSION}

PKU incidence in China during the period 2013-2017 is intermediate on the global level, and it is substantially higher in the north than in the south of the country. The provinces with the highest incidence are Gansu, Ningxia and Qinghai. The disease shows positive spatial autocorrelation, with Gansu, Ningxia, Qinghai and Shanxi appearing as HH cluster areas. Health authorities should strengthen screening, early diagnosis and family support measures in high-incidence provinces.

Acknowledgements We thank the nurses in the obstetrics and paediatric departments of the sampled maternity hospitals for collecting blood samples. We also thank the laboratory technicians and paediatric endocrinologists at the newborn screening centres for performing testing, diagnosis, treatment and follow-up, as well as the staff at those centres for their continuing support of the CNBSIS.

Contributors HML and JZ contributed to study design. LCX, JT, KD, XHL, QL, $X L Y, J L, E L Y, H Q W, H M L$ and JZ contributed to data acquisition. LCX, JT and MXW analysed the data. LCX wrote the first draft of the manuscript, which all authors revised and approved for publication.

Funding This work was supported by The National Key Research and Development Program of China (2017YFC1001700), The Special Project for Basic Work of Science \& Technology (2014FY110700) and The Sichuan University 'Interdisciplinary Major-Drive-through Type' Special Project of Personnel Training (SCUKG072).

Map disclaimer The depiction of boundaries on the map(s) in this article do not imply the expression of any opinion whatsoever on the part of BMJ (or any member of its group) concerning the legal status of any country, territory, jurisdiction or area or of its authorities. The map(s) are provided without any warranty of any kind, either express or implied.

Competing interests None declared.

Patient consent for publication Not obtained.

Ethics approval The study was approved by the Ethics Committee of West China Second University Hospital, Sichuan University (approval no. 2015011).

Provenance and peer review Not commissioned; externally peer reviewed.

Data availability statement № additional data are available.

Open access This is an open access article distributed in accordance with the Creative Commons Attribution Non Commercial (CC BY-NC 4.0) license, which permits others to distribute, remix, adapt, build upon this work non-commercially, and license their derivative works on different terms, provided the original work is properly cited, appropriate credit is given, any changes made indicated, and the use is non-commercial. See: http://creativecommons.org/licenses/by-nc/4.0/.

\section{REFERENCES}

1. Scriver CR. Phenylketonuria - genotypes and phenotypes. N Engl J Med Overseas Ed 1991;324:1280-1.

2. Williams RA, Mamotte CDS, Burnett JR. Phenylketonuria: an inborn error of phenylalanine metabolism. Clin Biochem Rev 2008;29:31-41.

3. Wang L, Zou H, Ye F, et al. Household financial burden of phenylketonuria and its impact on treatment in China: a crosssectional study. J Inherit Metab Dis 2017;40:369-76.

4. Dawson C, Murphy E, Maritz C, et al. Dietary treatment of phenylketonuria: the effect of phenylalanine on reaction time. $J$ Inherit Metab Dis 2011;34:449-54.

5. Blau N, van Spronsen FJ, Levy HL. Phenylketonuria. Lancet 2010;376:1417-27

6. Zeinalzadeh $\mathrm{AH}$, Talebi M. Neonatal screening for congenital hypothyroidism in East Azerbaijan, Iran: the first report. J Med Screen 2012;19:123-6.

7. Alm J, Larsson A. Evaluation of a nation-wide neonatal metabolic screening programme in Sweden 1965-1979. Acta Paediatr 1981;70:601-7.

8. Wamberg E. Incidence and distribution of pku-cases in Denmark. Ir Med J 1976;69:395-6.

9. Gu XF, Chen RG. Current status of neonatal screening in China. $J$ Med Screen 1999;6:186-7.

10. XF G, WZ. Screening for phenylketonuria and congenital hypothyroidism in 5.8 million neonates in China. Chin J Prev Med 2004;38:99-102.

11. Cao Y, Yuan P, Wang YP, et al. The profile of newborn screening coverage in China. J Med Screen 2009;16:163-6.

12. Lai T, XH L, Deng K, et al. Analysis on neonatal screening coverage rate in China from 2006 to 2016. Maternal and Child Health Care of China 2018;33:3601-4.

13. Zhan J-Y, Qin Y-F, Zhao Z-Y. Neonatal screening for congenital hypothyroidism and phenylketonuria in China. World $\mathrm{J}$ Pediatr 2009;5:136-9.

14. Gu X, Wang Z, Ye J, et al. Newborn screening in China: phenylketonuria, congenital hypothyroidism and expanded screening. Ann Acad Med Singapore 2008;37(12 Suppl):107-10.

15. Zhong $\mathrm{K}$, Wang W, He F, et al. The status of neonatal screening in China, 2013. J Med Screen 2016;23:59-61.

16. Deng K, He C, Zhu J, et al. Incidence of congenital hypothyroidism in China: data from the National newborn screening program, 20132015. J Pediatr Endocrinol Metab 2018;31:601-8.

17. Ministry of Health PRC. Technical specification for diagnosis and treatment of phenylketonuria and congenital hypothyroidism. J Child Health Care 2011;19:190-1.

18. Blau N, Burton B, Thony B, et al. Phenylketonuria and $\mathrm{BH} 4$ deficiencies. Bremen: UNI-MED, 2010: 14-7-36p.

19. Ye J, XF G. Interpretation of 'Consensus on Diagnosis and Treatment of Hyperphenylalaninemia Hemorrhage'. Chin J Pediatr 2014;52:430-2.

20. Rothman KJ, Boice JJ. Epidemiologic analysis with a programmable calculator. Boston: MA: Epidemiology Resources Inc, 1982.

21. Jin L, Su B. Natives or immigrants: modern human origin in East Asia. Nat Rev Genet 2000;1:126-33.

22. Kirby RS, Delmelle E, Eberth JM. Advances in spatial epidemiology and geographic information systems. Ann Epidemiol 2017;27:1-9.

23. Lee DH, Koo SK, Lee K-S, et al. The molecular basis of phenylketonuria in Koreans. J Hum Genet 2004;49:617-21. 
24. DiLella AG, Kwok SC, Ledley FD, et al. Molecular structure and polymorphic map of the human phenylalanine hydroxylase gene. Biochemistry 1986;25:743-9.

25. Mitchell JJ, Trakadis YJ, Scriver CR. Phenylalanine hydroxylase deficiency. Genet Med 2011;13:697-707.

26. Lo WH, Wang T, Eisensmith R, et al. Molecular basis of PKU in China. Chin Med Sci J 1993;8:180-5.

27. Zhang $\mathrm{M}, \mathrm{XF}$ G, Zhang $\mathrm{MH}$, et al. Mutations and their frequencies in exon 7 of phenylalanine hydroxylase gene of phenylketonuria in southern Chinese. Chin J Med Genet 1995;12:324-7.

28. WP H, Lai M, Zhang QZ, et al. Study on mutation diversity of phenylalanine hydroxylase gene in two groups of Chinese and one group of Japanese. Chin J Med Genet 1997;14:344-7.
29. Daniele A, Scala I, Cardillo G, et al. Functional and structural characterization of novel mutations and genotype-phenotype correlation in 51 phenylalanine hydroxylase deficient families from southern Italy. Febs J 2009;276:2048-59.

30. Guldberg P, Levy HL, Hanley WB, et al. Phenylalanine hydroxylase gene mutations in the United States: report from the maternal PKU collaborative study. Am J Hum Genet 1996;59:84-94.

31. Mao XM, XY M, HY L, et al. Investigation on current situation of screening of neonatal diseases in Ningxia Hui autonomous region. Maternal and Child Health Care of China 2012;27:5988-90.

32. Lai SP, Ren HM, Hu HT, et al. [HLA-DRB gene in Han, Hui, Uygur and Tibetan nationalities in northwest China]. Yi Chuan Xue Bao 1999;26:447-57. 
Correction: Phenylketonuria incidence in China between 2013

and 2017 based on data from the chinese newborn screening information system: a descriptive study

Xiang L, Tao J, Deng K, et al. Phenylketonuria incidence in China between 2013 and 2017 based on data from the Chinese newborn screening information system: a descriptive study. BMJ Open 2019;9:e031474. doi: 10.1136/bmjopen-2019-031474

This article was previously published with error in Figure 3.

The unit of incidence (horizontal ordinate) in figure 3 has been corrected to 100000 . The revised figure is below:

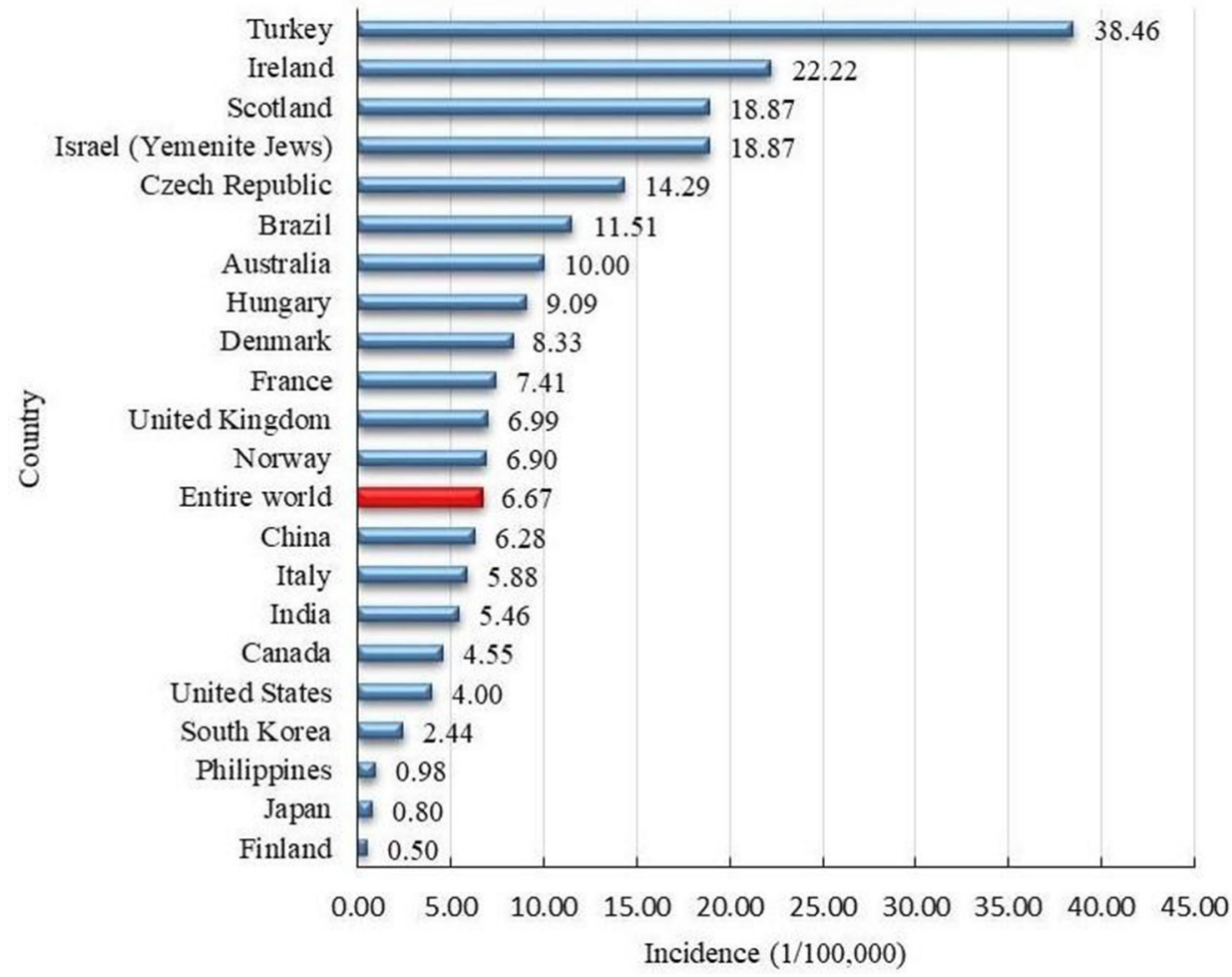

Figure 3 Phenylketonuria incidence by country.

Open access This is an open access article distributed in accordance with the Creative Commons Attribution Non Commercial (CC BY-NC 4.0) license, which permits others to distribute, remix, adapt, build upon this work non-commercially, and license their derivative works on different terms, provided the original work is properly cited, appropriate credit is given, any changes made indicated, and the use is non-commercial. See: http://creativecommons.org/licenses/by-nc/4.0/.

(C) Author(s) (or their employer(s)) 2020. Re-use permitted under CC BY-NC. No commercial re-use. See rights and permissions. Published by BMJ.

BMJ Open 2020;10:e031474corr1. doi:10.1136/bmjopen-2019-031474corr1

A) Check for updates 